\title{
L'aménagement durable des landes pastorales montagnardes : mythe ou réalité ? I. La lande de callune, Calluna vulgaris (L.) Hull
}

\author{
P. Loiseau, F.-X. de Montard
}

Inra agronomie, 234, av. du Brézet, Clermont-Ferrand, France

L'existence de landes pastorales sur les hautes terres du Massif Central est étroitement liée à des modalités de mise en valeur pluri-séculaires qui se sont lentement éteintes de 1850 à nos jours. Après les défrichements anciens, il a fallu entretenir la fertilité des terres cultivées. Sur le finage villageois, les transferts de déjections ovines des zones pastorales vers les champs ont progressivement établi une oligotrophie prononcée dans les parcours, faisant évoluer la végétation vers des pelouses très pauvres, à nard (Nardus stricta), ou à fétuque capillaire (Festuca capillata). Dans les Monts Dômes, les callunaies se sont développées aux dépens des pelouses à nard par baisse de l'intensité de pâturage en dessous de 2,5 brebis par ha. Elle était traditionnellement rajeunie par le feu ou la fauche: de jeunes pousses de callune se développaient rapidement, produisant $2 \mathrm{t}$ de MS $\cdot \mathrm{ha}^{-1} \cdot \mathrm{an}^{-1}$ de feuilles dont $60 \%$ sont consommées. Sans intervention, la callunaie accumule $10 \mathrm{t} \cdot \mathrm{ha}^{-1} \mathrm{de}$ MS en peu d'années et se stabilise à un stade de maturité peu appété produisant beaucoup de litière. Après 20 ans, elle accumule du bois et est progressivement envahie par le pin sylvestre. A l'inverse, toute intensification, le parcage, la pose de clôture et la fertilisation, la transformerait en prairie, Aujourd'hui, un pâturage modéré par les ovins ne suffirait pas à éradiquer les jeunes arbres. Le rajeunissement par la fauche avant la fin du cycle est un complément nécessaire.

\section{L'aménagement durable des landes pastorales montagnardes : mythe ou réalité ? II. La lande à genêt, Cytisus scoparius (L.) Link}

\author{
P. Loiseau, F.-X. de Montard
}

\section{Inra agronomie, 234, av. du Brézet, Clermont-Ferrand, France}

Sur les terres hautes du Massif Central, les paysans des siècles passés entretenaient la fertilité des champs par le pacage ovin ou l'épandage de fumier. Une autre technique consistait à semer le genêt dans la jachère pour obtenir un excellent combustible (fours à pain) et accroître la fertilité grâce à la pénétration des racines et à la fixation symbiotique de l'azote. Cette légumineuse a une croissance rapide et exclusive. Elle est facile à semer et à arracher. Depuis, nombre de ces champs ont été transformés en pâturages envahis par un peuplement équienne dense de genêts se renouvelant selon un cycle d'environ 15 ans incluant une phase d'enherbement, plus ou moins marquée selon la pression pastorale exercée, entre le vieillisement et la reconstitution du peuplement. En l'absence de troupeaux, le genêt abrite et facilite l'installation d'espèces forestières conquérantes comme la fougère, le noisetier, le pin et le bouleau. La lande à genêt est donc une phase instable dans l'évolution de la végétation. La suppression du genêt par le feu ou par le broyage mécanique aboutit rapidement à une levée en masse des graines en stock dans le sol qui ne peut être maîtrisée que par la mise en culture ou un pâturage insistant. Le maintien de l'activité pastorale sur les zones envahies exige une intervention raisonnée, combinant le broyage et le pâturage ; la surface à broyer doit être modulée en fonction des animaux disponibles pour l'entretien du terrain ainsi découvert. 